\title{
Os primórdios da doença
}

\author{
The begining of the Disease
}

\author{
Aluízio Prata*, João Carlos Pinto Dias**, José Rodrigues Coura***
}

\begin{abstract}
RESUMO
A partir do ciclo enzoótico silvestre do Trypanosoma cruzi, a doença de Chagas humana (DCH) emergiu esparsa e focalmente em diferentes pontos do Continente Americano, havendo inícios de sua ocorrência em épocas pré cristãs. Dispersada por subsequentes hordas de migrações internas, a DCH instalou-se em locais onde os insetos vetores se domiciliavam e diferentes reservatórios se aproximavam dos assentamentos humanos. Ganhou maior expansão no período pós colombiano, em particular entre o final do século XIX e meados do século XX, quando atingiu seus picos de prevalência. Nos primórdios da doença há indícios esparsos de casos agudos, cardiopatia crônica e megacólon em diferentes pontos da Região, mas esses quadros se encontram sujeitos a confusão diagnóstica. Por outro lado, o megaesôfago se mostra o marcador de maior especificidade na $\mathrm{DCH}$, havendo numerosos registros de sua ocorrência em vários pontos do Brasil, especialmente a partir do século XVIII. O peso médico social da DCH corresponde inequivocamente à ocorrência da cardiopatia chagásica crônica, tendo sido a partir justamente de sua caracterização que foram deflagradas em definitivo as ações de controle da enfermidade nos países endêmicos.
\end{abstract}

Palavras-chave: Doença de Chagas. Histórico. Evolução.

\section{ABSTRACT}

Originating from the ancient enzootic cycle of Trypanosoma cruzi, human Chagas disease (HCD) emerged focally in different points of America, in the Pre Christian period. Being slowly expanded as a consequence of internal migrations, HCD was settled in those locals where some vector species reached domiciliation and where different kinds of reservoirs entered in domestic environment, with major expression in the post Columbus era, particularly between the final of XIX Century and the middle of XX Century, when the maximum prevalence rates were attained. Originally, scarce evidences of acute cases, chronic cardiopathy and megacolon could be detected in different points of the Region, but the diagnosis of such clinical pictures was not easily ascertained. Nevertheless, the megaoesophagus picture proved to be the more specific marker of ancient HCD, with several descriptions of its occurrence in different Brazilian regions, mainly since the XVIII Century. The social burden of HCD depends basically of the presence of chronic cardiopathy, and only after its recognition, control actions of the disease were definitely lounged in endemic countries.

Key-words: Chagas Disease. Historic. Evolution.

A circulação do Trypanosoma (Schyzotripanum) cruzi na natureza é bastante antiga, remontando a muitos milhares de anos. Segundo Hoare ${ }^{1}$, o processo histórico da evolução dos tripanossomos Stercoraria viria, primitivamente, de invertebrados aquáticos, circulando posteriormente pelo tubo digestivo de peixes, répteis e anfíbios. Muito mais tarde, insetos predadores desenvolveram a hematofagia e se acercaram do flagelado, assim possibilitando a transmissão do parasita a distintos hospedeiros que lhes serviam de fonte alimentar. Por evolução seletiva, o grupo cruzi inicialmente adaptou-se a hemípteros hematófagos e a mamíferos de médio e pequeno porte, no âmbito das áreas de dispersão dos invertebrados vetores, assim configurando o ciclo enzoótico silvestre primitivo, já no âmbito do Continente Americano. Isto porque, conforme Schofield ${ }^{2}$, o ponto de partida para a linha histórica da tripanossomíase americana silvestre remonta ao final da era mezozóica, na região austral do supercontinente, a partir de ciclos primitivos do T. cruzi em marsupiais. Mais posteriormente o ciclo expandiu-se para outros mamíferos através do comportamento eclético dos triatomíneos, com tendência,

*Universidade Federal do Triângulo Mineiro, Uberaba, MG.

**Centro de Pesquisas René Rachou, FIOCRUZ, Belo Horizonte, MG.

*** Instituto Oswaldo Cruz, FIOCRUZ, Rio de Janeiro, RJ.

Endereço para correspondência: Dr. João Carlos Pinto Dias. Instituto René Rachou. Av. Augusto de Lima 1715, Barro Preto, 30190-002 Belo Horizonte, MG, Brasil.

e-mail: jcpdias@cpqrr.fiocruz.br em geral, de baixa patogenicidade. O marco acadêmico mais aceito para tal evolução advém da Teoria dos Focos Naturais de Pavlowsky, assim resumida por Silva3:

Muitas doenças, e em especial as zoonoses, têm habitats naturais em ecossistemas bem definidos nos quais patógenos, vetores $e$ hospedeiros naturais formam associações, ou biocenoses, em que o patógeno circula. A paisagemé, assim, um fator epidemiológico, pois suas características são as do ecossistema local. A ocupação do homem de tais focos naturais leva à ocorrência de casos de doença. A doença passa a ter personalidade própria e incorpora-se ao contex to ecológico, sendo vista como parte integrante do ecossistema (p. 20).

Recentes especulações situam a diferenciação entre os dois grupos primordiais de T. cruzi caracterizados bioquímica e molecularmente, estando o grupo I basicamente ligado a uma evolução primitiva em marsupiais e o grupo II, provavelmente posterior, a primatas. O T cruzi I refere-se à maioria dos isolados da selva amazônica e de transmissão doméstica ao norte da linha equatorial, estando originariamente vinculado ao gênero Didelphis, de larga distribuição em toda a América. O grupo II está associado com a maioria dos casos humanos da América Austral, especialmente espalhado no Cone Sul através de populações domésticas de Triatoma infestans. Supõese que T. cruzi II tenha sido originado do grupo I, transferido de marsupiais para primatas e roedores que emergiram na América do Sul 25 milhões após os marsupiais. Outra hipótese situa esta propagação a partir de edentados que compartiam seus nichos terrestres com roedores e uma série grande 
de triatomíneos rupestres ${ }^{4,5}$. Em tal contexto, estudando as seqüências nucleotídicas da subunidade 18 S e o RNA ribosomal de triatomíneos americanos, Bargues ${ }^{6}$ pôde estabelecer que populações das tribos Triatominii e Rhodniini evoluíram a partir de ancestrais predadores durante o Cretáceo, entre 22 e 64 milhões de anos, quando a América do Sul já estava separada da África, explicando a ausência desses triatomíneos no Continente Africano, e portanto, da tripanossomíase cruzi. Como o T. cruzi emerge há cerca de 100 milhões de anos, o ciclo silvestre significou historicamente a origem do que se veio a chamar doença de Chagas, estabelecendo-se o ciclo humano doméstico muito mais tarde. A tripanossomíase silvestre persiste e se encontra largamente espalhada nas Américas, significando, na atualidade, o principal resíduo da circulação do parasita e o conseqüente fator de risco para uma eventual recrudescência da transmissão da doença humana. A interação epidemiológica entre os ciclos far-se-á paulatinamente, envolvendo situações complexas de transmissão do T. cruzi. Envolve a biocenose de inúmeros reservatórios com pelo menos cento e vinte espécies de vetores, de variados hábitos de vida, em paralelo com transmissão oral do parasito, com ciclos especiais deste em glândulas anais de didelfídeos, com ações antrópicas cada vez mais intensas e com incursões espúrias de humanos no ambiente natural ${ }^{2,7,8,9,10}$. A esquizotripanose humana terá como origem o acercamento do homem aos nichos enzoóticos primitivos. Neófito na relação com o parasito, o homo sapiens irá sofrer as mazelas de uma infecção que não era patogênica para os vetores e a imensa maioria dos reservatórios naturais. Acontecerá de início em focos insulados de interação homem com o triatomíneo, em pontos variados do Continente ${ }^{2,11,12}$. A expansão da doença se deverá ao assentamento e concentração de populações humanas, em épocas pré-colombianas. Complementar e decisivamente, a endemia se consolidará depois da invasão européia, especialmente no final do século XIX e na primeira metade do século XX, em face a mui precárias relações de produção de uma população rural crescente, à vivenda rural de má qualidade, às migrações humanas e, novamente, às ações antrópicas sobre o ambiente $\mathrm{a}^{4,8,11,13}$.

Existem indícios de que a infecção humana pelo T. cruzi ocorre há pelo menos cinco mil anos AC, época em que populações nômades do deserto de Atacama (Chile) estabeleceram uma rota entre o mar e as montanhas: em múmias da época, recuperadas desta Região, identificaram-se resquícios moleculares do $T$. cruzi ${ }^{11,12}$. Certamente, os povos primitivos das Américas conheciam os triatomíneos que viviam nas proximidades de suas casas diferenciando-os de predadores e fitófagos (coreideos), sendo que, alguns destes lhes serviam de alimentos. Vários autores estabelecem como crucial o assentamento de povos quéchuas no altiplano boliviano, em casas muito primitivas, ali desenvolvendo o hábito de criar a domicílio roedores silvestres (preás), que trouxeram o parasito para o domínio humano ${ }^{2,10,11}$.

Indubitavelmente, o marcador mais remoto e consistente da tripanossomíase nas Américas consiste no registro da presença dos vetores invertebrados, aliás, ponto de partida fundamental na descoberta de Carlos Chagas ${ }^{2,14}$. Entre os cronistas e viajantes que escreveram sobre os triatomíneos, Velazco e Rivas esquematizam a seguinte cronologia ${ }^{15}$ :

Francisco López de Gomara (1514) "Hay muchas garrapatas y chinches con alas" (El Darien, Panamá), posiblemente refiriéndose a Rhodnius pallescens o a T. dimidiata.
En 1523 Antonio de Herrera publicó: Francisco de Garay en Pánuco, Veracruz (México), el ejercito expedicionario fue victima de... "molestias de los mosquitos i pitos, que pican y dejan señal como chinches, i suelen causar calenturas". (En algunos lugares a los triatóminos de América se les conoce como pitos) y probablemente Herrera, se refirió a T. dimidiata, común en esa región.

En 1535, Gonzalo Fernández de Oviedo dijo acerca de las Islas de Chara o San Lucas y Potosí (Golfo de Nicaragua): "Para mi fue cosa nueva y enojosa, de muchas chinches en los bohíos, con alas, e no parecen de día, ni avía pocas de noche, e son mas diligentes e prestas y enojosas que las de España, e pican mas mayores que aludas grandes... I estas chinches en toda la provincia de Nicaragua las hay". Sin embargo en la época moderna, fue hasta 1949, cuando se describió el primer caso autóctono de enfermedad de Chagas en Nicaragua, y es hasta entonces, cuando se observaron chinches infectadas. Seguramente Gonzalo Fernandez de Oviedo, se refirió a Rhodnius prolixus, común en la actualidad en esos lugares.

En 1569, Fray Bernardino de Sahagú informó que en Nueva España: "hay muchas cucarachuelas que son pardillas y tienen dos maneras de alas con las que vuelan, son ponzoñosas, donde pican imprimen comezón e hinchazón...", informando que desde entonces la infestación de la vivienda y su entorno, era común en México.

En 1590 Fray Ronaldo de Lizarraga, hizo la primera descripción de los triatóminos y sus hábitos hematófagos nocturnos en Argentina.

En 1591 Juan de Cárdenas, al tratar del reino de nueva Galicia, expresó: "Las chinches que llaman de compostela, en este Reino de la Nueva Galizia, mas enojosas y malas son que las arañas" (posiblemente Triatoma picturata o T. longipennis) comunes aún, en esa región.

En 1773-1775 De Gueer, según Usinger, realizó la primera descripción científica de los triatomas (T. rubrofasciata).

Entre 1781 y 1801, durante su estancia en Argentina, Felix de Azara, describió a los triatóminos argentinos y los llamó por primera vez, vinchucas, nombre quechua que se popularizó grandemente en ese país y más tarde en todo sudamérica.

En 1811 Latreille describió a Triatoma dimidiata y a Panstrongylus geniculatus, basado en los ejemplares capturados por Von Humboldt en Ecuador.

T. dimidiata, por otra parte, el triatómino más extendido en México y posiblemente el más importante como transmisor, fue registrado en este país por Champion en 1899.

Aparentemente la primera referencia en nuestro país, sobre la existencia de triatóminos posterior a los cronistas, fue realizada por Burmeister en 1835 y se trató de T. phyllosoma.

En 1848, Herich-Schaeffer, describió Conorhinus mexicanus (Triatoma mexicana) que ha tomado importancia en los últimos años.

De 1859 a 1900, Stäl hizo las contribuciones más importantes del siglo XIX, sobre la sistemática de los triatóminos, al estudiar los géneros Rhodnius, Eratyrus y Belminus y otros muchos triatominos.

Já muito cedo, Carlos Chagas iria antever a grande dispersão da tripanossomíase humana nas Américas, mercê dos registros bem sistematizados de um grande colaborador seu, Arthur Neiva, acerca de tratomíneos domiciliados e infectados com flagelados semelhantes ao T. cruzi por todo o Continente ${ }^{16,17}$. Como visto acima, os reportes de triatomíneos em contato com o homem, por nativos, cronistas e cientistas, já era antigo e 
bastante espalhado no Novo Mundo, sugerindo a que a moléstia humana antecedia a descoberta de Colombo ${ }^{2,6,12}$.

Com referência aos antecedentes de quadros clínicos humanos, como as espécies transmissoras são muitas, de variados padrões ecológicos e com distribuição regionalizada pelo continente, pode-se supor que os focos da enfermidade humana em seus primórdios tenham sido também esparsos e com distribuição variada, na dependência de fatores de aproximação do homem de nichos naturais dos triatomíneos. A se julgar pela distribuição das principias espécies implicadas no ciclo doméstico, é bastante provável, como assinalam vários autores ${ }^{2,3,6,11,12}$ que $T$. infestans foi o responsável fundamental pela tripanossomíase no Cone Sul, devendo ter ocorrido sua dispersão para Chile e Argentina em épocas muito antigas, a ver pelos achados de Atacama. Sua vinda para Uruguai e Brasil terá ocorrido muito depois, em épocas coloniais e do Império Brasileiro, alcançando São Paulo e Minas somente com a explosão do mercado do café, e sempre carreado pelo homem, a partir de ecótopos artificiais ${ }^{3}$. No Sudeste, Nordeste e Centro Oeste do Brasil, indícios da doença humana serão encontrados nos séculos XVIII e XIX, então dependentes de espécies nativas, especialmente de P. megistus (Mata Atlântica), T. brasiliensis e T. pseudomaculata (Caatinga) e, possivelmente, T. sordida (Cerrado) ${ }^{9}$. Na Venezuela o transmissor clássico foi Rhodnius prolixus, inseto de ambientes umbrosos assestado em diferentes tipos de palmeiras, posteriormente introduzido na América Central. 0 mais disperso dos triatomíneos ao norte do Equador é T. dimidiata, encontrado em focos naturais dispersos (campos, savanas, matas secundárias) e também carreado passivamente por migrantes e rotas náuticas, do México ao Equador ${ }^{2}$. A história natural da doença de Chagas (DCH) irá acontecer conforme o homem foi se aproximando dos nichos naturais dos vetores invertebrados, aos poucos propiciando a colonização de sua própria casa, de início focalmente, mais tarde, em extensas áreas, de modo maciço ${ }^{2,7,9}$.

Durante os séculos XVI e XVII, os colonizadores portugueses referem no Brasil, enfermidades regionais localmente apelidadas como mal do bicho, mal de engasgo e caseira (ou mal do $\mathrm{cu}$ ), possivelmente referindo-se a problemas esofágicos e intestinais (megacolon) causados por T. cruzi. Em 1882, morreu Charles Darwin de problemas cardiológicos, possivelmente devido à $\mathrm{DCH}$, aparentemente contraída durante suas missões científicas na América do Sul. Aliás, Darwin descreve claramente a presença de vinchucas na região de Mendoza, referindo-se tacitamente ter sido molestado pelo inseto ${ }^{11}$. Mais anteriormente, em cerâmicas peruanas provavelmente entre os séculos XIII e XVI, há uma peça que representa um rosto humano com flagrante edema bipalpebral e unilateral, idêntico ao sinal de Romana (Figura 1).

Conforme amplamente discutido, nas suas expressões mais visíveis, como a doença aguda e os quadros de cardiopatia avançada, a enfermidade humana não marcou suficientemente as crônicas e relatos dos séculos passados. O problema reside na pouca densidade do agravo em seus primórdios, a par da semelhança de vários outros quadros devidos a variadas etiologias, portanto passíveis de confusão diagnóstica e sem

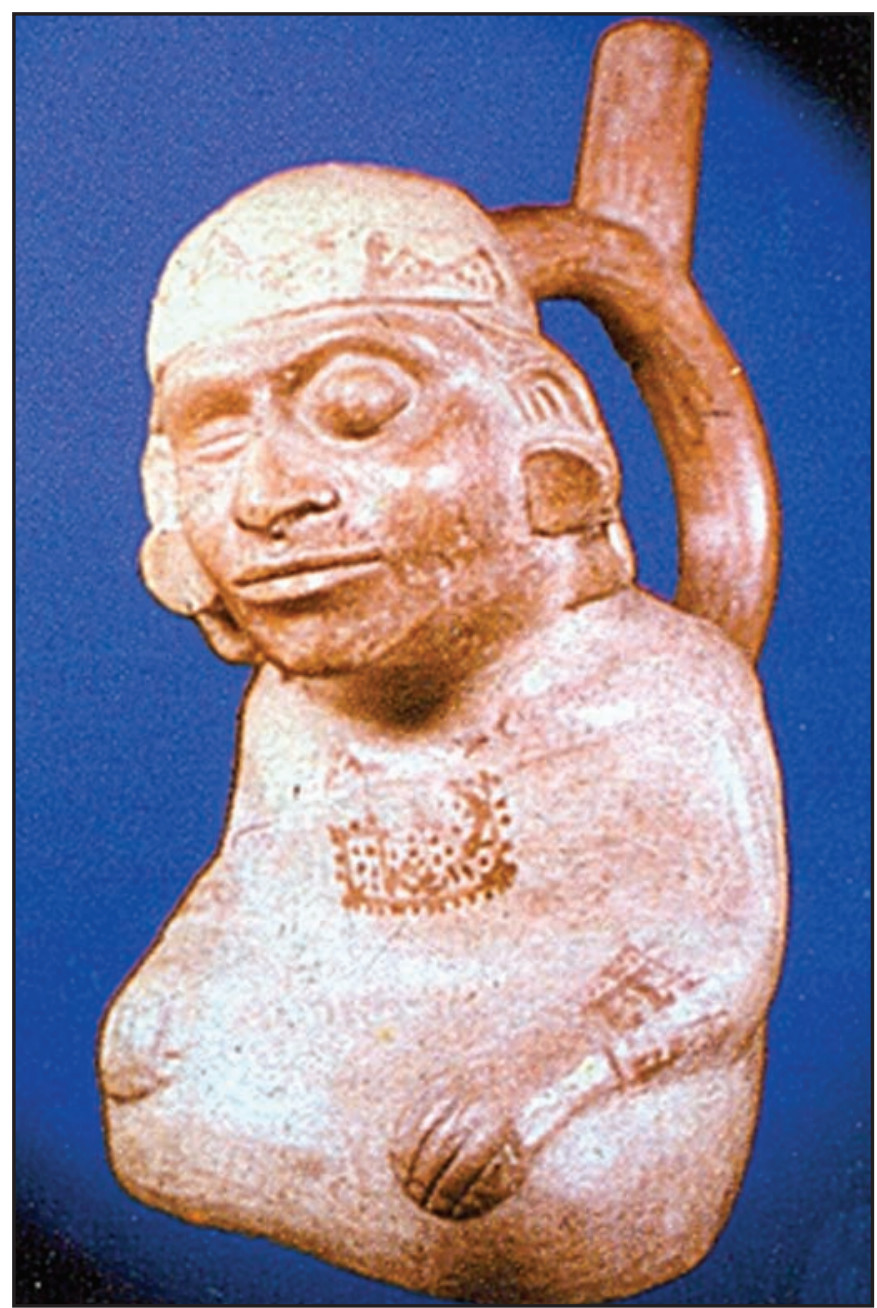

FIGURA 1 - Foto de cerâmica inca pré colombiana mostrando um edema bi palpebral e unilateral, muito semelhante ao "sinal de Romaña", depositada no Museu de Lima ${ }^{3}$.

a necessária especificidade ${ }^{3,18}$. No caso do complexo oftalmoganglionar, muito chamativo, os diagnósticos corriqueiros de miíase, conjuntivite, hordéolo, traumatismo e picaduras de inseto facilmente se imponham na realidade da época, com o agravante de desaparecem as manifestações em poucas semanas ${ }^{4,19,20}$. Particularmente, embora ausente na maioria dos pacientes com forma aguda, é notável como o sinal de Romaña foi importante no reconhecimento continental da DCH após a sua descrição, em 1935, apesar de ter sido visto pelo próprio Carlos Chagas em suas publicações originais, especialmente a de $1916^{21}$. No quadro abaixo, adaptado de Talice et $a^{22}$, observa-se a dispersão de casos agudos da enfermidade detectados nas três primeiras décadas após sua descoberta (Tabela 1).

Com a cardiopatia crônica chagásica (CCC) passou-se algo semelhante, apesar de acometer pelo menos 30\% dos infectados e hoje ser descrita em toda a área endêmica. Carlos Chagas teve o elevado mérito, em sua genialidade, de apontá-la e descrevê-la em seus pacientes, de forma magistral ${ }^{23,24,25}$. Nas áreas endêmicas da Argentina, Mazza, entre outros, tentaram debalde individualizá-la, apesar de reconhecerem a precisão dos relatos de Chagas $^{26}$.

No Brasil, a CCC foi pressentida e apontada por ilustres pesquisadores de Manguinhos (Lutz, Neiva, Belisario Penna e 
TABELA 1 - Sinopse histórica e dispersão da doença de Chagas aguda entre 1909 e 1939 (22).

\begin{tabular}{lcc}
\hline Países & $\begin{array}{c}\text { Ano de confirmação } \\
\text { do } 1^{\circ} \text { caso }\end{array}$ & $\begin{array}{c}\text { № aproximado de } \\
\text { casos confirmados }\end{array}$ \\
\hline Brasil & 1909 & 33 \\
El Salvador & 1913 & 2 \\
Venezuela & 1919 & 20 \\
Peru & 1919 & 2 \\
Argentina & 1924 & $550^{*}$ \\
Equador & 1929 & 2 \\
Panamá & 1931 & 20 \\
Guatemala & 1934 & 3 \\
Uruguai & 1937 & $119^{* *}$ \\
Chile & 1939 & 1 \\
México & 1939 & 1 \\
\hline *maioria após descrição de Romaña. & \\
**83\% com sinal de Romaña. & &
\end{tabular}

especialmente Eurico Villela), não apenas revendo os casos de Lassance como identificando o agravo em amplas extensões do Norte de Minas, de Goiás e do Nordeste (Bahia, Pernambuco e Piauí), como também em região urbana (hospitais de Belo Horizonte), em trabalhos realizados entre os anos 1912 e $1935^{16,25,26,27,28}$. Algumas destas descrições são mais genéricas, geralmente conectando a ocorrência de cardiopatias com informações sobre triatomíneos na área. Outras, como as de Villela em hospitais mineiros ${ }^{28}$, já trazem maior descrição semiótica e também fazem ilações epidemiológicas sobre a origem dos pacientes, inclusive registrando a concomitância, em alguns casos, de megaesôfago e do megacólon. De modo geral, apreende-se, por estes relatos, que a CCC já estava bastante disseminada no país, abrangendo extensas áreas no Sudeste, Centro Oeste e Nordeste. Em paralelo, ponteavam informações sobre casos crônicos em São Paulo, no Paraná e no Rio Grande do Sul. Os grandes marcadores da CCC foram indubitavelmente a morte súbita entre pessoas jovens de origem rural e as severas arritmias cuja etiologia os médicos da Colônia e Império não atinavam, eventualmente atribuindoas à beri-beri e ao mal gálico ${ }^{24,29}$. As populações ribeirinhas relatavam sua ocorrência através de expressões vagas como avexame e baticum, registradas por Chernoviz, antes de Chagas, e posteriormente por este e companheiros de Manguinhos (Lutz, Neiva, Machado, Penna) ${ }^{25,28,30,31}$. Pode-se estimar que a CCC existia dispersa entre os focos domésticos primitivos da esquizotripanose, atenuada em sua expressão epidemiológica pelo não reconhecimento e, especialmente, pelo isolamento e baixa densidade demográfica dos assentamentos rurais latino-americanos dos séculos XVIII e XIX. Com efeito, o próprio Chagas irá afirmar que foi somente com a chegada da estrada de ferro que a intensidade da infestação pelo Conorrhynus se fez patente, ensejando consequentemente a emergência de casos agudos em Lassance ${ }^{14}$. Por outro lado, o genial cientista relatará claramente, em 1912, 1916 e 1922, que ao tempo da descoberta já se deparara com muitos casos

*Observação: Este texto da $10^{\mathrm{a}}$ edição (1886) encontra-se repetido na $13^{\mathrm{a}}$. Edição (1888) e na 18ª . Edição (1908). Uma primeira menção mais reduzida é encontrada na $2^{\mathrm{a}}$. Edição, em 1868. de cardiopatia crônica, atribuíveis ao T. cruzi, e que certamente já estariam infectados há décadas, conforme a história natural da moléstiaa ${ }^{19,24,27}$. Em que pese sua grande relevância epidemiológica e médico-social, a CCC só foi reconhecida e totalmente caracterizada nos anos 1940, mercê de cuidadosos e sistematizados estudos de Dias, Laranja e Nóbrega (discípulos de Chagas) em Bambuí, Minas Gerais, aliando a observação clínica e eletrocardiográfica com estudos epidemiológicos e anátomo-patológicos $25,27,32$.

Na sequência, trabalhos memoráveis de Ramos et al, em São Paulo, de Rosembaum e Cerisola, na Argentina, de Pífano e Pieretti, na Venezuela, entre outros, consolidaram o reconhecimento da CCC e demonstraram sua ocorrência ao longo do Continente, quase sempre a partir da conjugação de inquéritos populacionais de sorologia e eletrocardiografia ${ }^{17,25}$. Para tanto, o desenvolvimento da eletrocardiografia e a sistematização dos quadros mais típicos da cardiopatia chagásica foram fundamentais, transcorrendo especialmente a partir dos trabalhos de Francisco Laranja ${ }^{27,29}$. Em paralelo, a reprodução experimental das cardiopatias chagásicas aguda e crônica em animais de laboratório, especialmente o cão e o macaco, consolidou de vez a interpretação definitiva da patogenia e da evolução da manifestação mais importante da $\mathrm{DCH}^{25,27,32}$. Aliás, é amplamente admitido pelos estudiosos que foi a partir do reconhecimento da cardiopatia chagásica por cientistas, sanitaristas e autoridades sanitárias que emergiram em toda a América as principais decisões políticas que resultaram no controle da enfermidade ${ }^{3,13,25}$.

Conforme Silva, no entanto, o marcador mais fiel da dispersão da esquizotripanose humana nos tempos coloniais e imperiais do Brasil, terá sido o megaesôfago, por seu quadro inconfundível e a alta especificidade da infecção pelo T. cruzi $i^{3}$ Foi relatado amplamente no Estado de São Paulo, Minas Gerais, Brasil Central e Nordeste, por cronistas, farmacêuticos, médicos gerais e cirurgiões, especialmente a partir do século XVIII ${ }^{30,31,33,34,35}$. Carlos Chagas o menciona em 1916, concomitantemente com Neiva e Pena, que o descrevem minuciosamente em vasta área de Minas Gerais, Goiás e Nordeste ${ }^{21,36}$. Em Minas, Villela tece especulações sobre as relações entre a afecção e a tripanossomíase entre 1920 e 1930, mas somente a partir de 1950, Fritz Köberle estabelece definitivamente a etiologia chagásica do megaesôfago endêmico no Brasil $28,33,37,38,39$. As descrições do megaesôfago endêmico no Brasil por volta dos séculos XVIII e XIX são muitas e bastante precisas. Por exemplo, Chernoviz (apoiado em sua própria vivência e no relato de médicos, práticos e farmacêuticos que contatava pelo País, apensa as seguintes informações no seu clássico Dicionário de Medicina Popular, desde $1868^{31 *}$ :

Mal de engasgo, dysphagia ou esophagismo - Difficuldade ou impossibilidade de engulir, produzida pela contracção espasmódica do pharynge ou do esophago. Sobrevem durante a comida. De repente, a pessoa vê-se na impossibilidade de engulir, e quase sempre parece-lhe que um corpo estranho ficou parado no estomago. Se o espasmo existir na extremidade superior, as substancias introduzidas voltão para cima immediatamente; se occupar, pelo contrario, a 
extremidade inferior, a regurgitação tem lugar algum tempo depois da ingestão dos alimentos. O espasmo pode desapparecer passadas algumas horas, ou persistir sem interrupção durante muitos dias; durando mais de doze dias, occasiona a morte por inanição; outras vezes apparece com certos intervallos, e existe livres; examinando enquanto dura o accesso, acontece às vezes que o estreitamento desapparece durante a introdução da sonda. Tratamento: Clyster de assafétida (290). Fricções no pescoço com pomada de belladona (308), com balsamo tranquilo (390), com linimento opiado (641), com óleo canforado (328), com linimento de chloroformio (380). Engulir gelo aos pedaços. Introduzir sonda esophagica no esophago até o ponto de constricção. Injeções subcutâneas com solução de sulfato de atropina (293). Eletricidade (423).

No texto acima, entre parênteses estão os números indicativos de cada procedimento, no bojo do Dicionário.

Com o megacólon haveria por certo muita confusão diagnóstica, devido à inespecificidade do quadro de obstipação e uma série enorme de diagnósticos diferenciais. Não obstante, na mesma área visitada por Neiva e Pena, em $1912{ }^{36}$, a caseira é mencionada em pessoas mais idosas e em menor proporção que o mal de engasgo, com certa freqüência superpondose a casos de arritmias cardíacas. Também os quadros de obstipação importante e vólvulos da sigmóide são conhecidos há muitas décadas ao longo do altiplano andino, em áreas muito infestadas por triatomíneos (muitos foram os relatos locais de médicos e da população aos AA deste trabalho, com registros seguramente muito anteriores à descoberta de Carlos Chagas). Neste último caso, no entanto, há que atentar-se para um outro fator de confusão, qual seja a ocorrência de um megacólon das alturas sem infecção chagásica, em paralelo com indivíduos portadores de megacólon e sorologia para T. cruzi positiva.Os registros indicam grande dispersão de ambos os agravos, indo do norte daArgentinaatéo Equador, sempre emmaiores altitudes ${ }^{20,39}$.

De todo o exposto, pode-se inferir que a doença de Chagas humana é muito antiga no Continente Americano, provavelmente advinda da enzootia silvestre primitiva, amplamente dispersa. Em seus pródromos, a DCH aconteceu focalmente em diversos e distintos rincões do Continente, ganhando maior incidência após a conquista européia, mais particularmente em função de maior ação antrópica, de migração e de assentamentos rurais muito pobres. Este incremento foi exacerbado com o progressivo aumento da densidade demográfica em áreas rurais do continente, processo que teve seu pico entre a segunda metade do século XIX e a metade do século XX, coincidindo com intensa abertura de vias rodoviárias e férreas em todos os países, assim como foi exacerbada a ação do homem sobre o ambiente, com a abertura de novas fronteiras agrícolas, em paralelo com grande pobreza e péssimas habitações em toda a região $0^{3,713}$. Nesta fase, especialmente nas primeiras décadas do Sec.XX, houve intensa e progressiva dispersão de T. infestans no Cone Sul e de R. prolixus a partir da Venezuela, alcançando picos extremos de infestação domiciliar, também o fazendo P. megistus, em algumas áreas de Minas Gerais e da Bahia ${ }^{8,9,10}$. Foi um período relativamente longo, em que a densidade triatomínico-tripanossômica em ecótopos artificiais propiciou não apenas a descoberta da doença como os elevados índices de casos agudos e infectados crônicos nas áreas infestadas ${ }^{3,18}$. Com a descrição definitiva da cardiopatia chagásica e a generalização de inquéritos sorológicos e eletrocardiográficos em toda a América Latina, conjuntamente com maior movimentação da comunidade científica em torno da DCH e seu controle, a doença ganhou interesse e progressiva prioridade ${ }^{17,40,41}$. Após os anos 1960 houve progressivo descenso na prevalência, devido à intensificação das ações de controle, ao êxodo rural urbano, à modernização do interior e ao efeito da mortalidade em populações infectadas ${ }^{3,8,18}$. Alguns trabalhos também assinalaram, a partir desse período, o decréscimo da morbi-mortalidade da DCH em áreas sob controle, fato eventualmente dependente da superposição de fatores como redução de reinfecções exógenas e melhor atenção médica e securitária para os infectados ${ }^{18,42,43}$.

Em resumo, algumas etapas distintas podem ser arroladas na história evolutiva da DCH, ao longo do Continente Americano. Uma etapa inicial remonta a casos muito esporádicos e em situações focais, mercê de contatos casuais entre o homem e vetores silvestres infectados, ocorrente na era pré cristã e se estendendo até provavelmente períodos pré incaicos e pré maias, envolvendo situações de penetração em matas, caça etc. Numa segunda etapa, que vai até a chegada européia (finais do século XV), alguns focos endêmicos poderão ter aparecido em assentamentos mais populosos de diversas etnias nativas, em espaços abertos eventualmente ligados a nichos naturais da enzootia primitiva, situações que incluíram a domiciliação de alguns vetores, o afluxo de animais sinantrópicos e os hábitos emergentes de criar roedores nativos em casa, como fonte de proteínas. A terceira etapa surge com a invasão luso-espanhola, dizimando populações nativas e provocando intermináveis migrações internas, com assentamentos precários em áreas interioranas e muita pobreza, gerando casas de péssima qualidade e durando até meados do século XIX, época da consolidação das independências na Região. Desta etapa surgem, concretamente, indícios de vetores domiciliares e marcadores da doença humana, em pontos diversos do continente. Segue-se uma etapa mais curta, que vai do final do século XIX a meados do século XX, como já referido, de endemicidade crescente e picos máximos de incidência e prevalência. A doença é então descoberta, estudada e reconhecida em toda a América Latina, pontificando as elevadas taxas de prevalência da cardiopatia crônica e gerando alta mortalidade e outros danos sociais. Em acréscimo, intensifica-se o emprego de transfusão de sangue em todos os países, por muitos anos sem controle adequado, o que aumenta substancialmente a incidência ${ }^{13,20,25}$. Será esta, acima de todas, a fase de maior impacto da doença, em termos de incidência, morbi-mortalidade e danos médico-sociais ${ }^{3,8,41}$. Uma última etapa, a partir dos anos 1960-70, situará o decréscimo da endemicidade, mercê de ações de controle (vetorial e transfusional), conjugadamente com o esvaziamento da população rural em amplas áreas da América Latina. A doença deverá ir perdendo sua visibilidade clínica, com a exaustão de novos casos, restando eventos isolados de transmissão por via oral e congênita, e outros em áreas mal trabalhadas, a depender de vigilância constante e da sustentação de sua prioridade no contexto dos governos envolvidos ${ }^{11,25,40,41}$. 


\section{REFERÊNCIAS}

1. Hoare C. The trypanosomes of mammals. Oxford: Blackwell Scientific Publications; 1972.

2. Schofield CJ. Overview: evolution of the Triatominae. In: Schofield CJ, Ponce C, editores. Proceedings of the Second International Workshop on Population Genetics and Control of Triatominae. México: INDRE; 1998. p. 46-48.

3. Silva LJ. A evolução da doença de Chagas no Estado de São Paulo. São Paulo: Hucitec Editora; 1999.

4. Miles MA, Yeo M, Gaunt MW. Epidemiology of American Trypanosomiasis. In: Maudlin I, Holmes PH, Miles MA, editors. The Trypanosomiasis. Oxfordshire: CABI Publishing; 2004. p. 243-251.

5. Zingales B, Stolf B, Souto RP, Fernandes O, Briones MRS. Epidemiology, Biochemistry and Evolution of Trypanosoma cruzi Lineages based on RNA sequences. Mem Inst Oswaldo Cruz 1999; 94 (suppl I): 159-164.

6. Bargues MD. Relojes moleculares y evolución genética de Triatominii y Rhodniini basados en el ADN Ribosomal. In: Schofield CJ, Gula FN editores. Proceedings of the Fourth Internacional Workshop on Population Genetics and Control of Triatominae. Bogotá: Universidad Los Andes ; 2000. p. 117-124.

7. Bucher EH, Schofield CJ. Economic assault on Chagas disease. New Scientist 1981; 92: 321-324.

8. Dias JCP, Coura, JR. Epidemiologia. In: Dias JCP, Coura JR, editores. Clínica e Terapêutica da Doença de Chagas: uma abordagem prática para o clínico geral. Rio de Janeiro: Editora FIOCRUZ; 1997. p. 33-66.

9. Forattini OP. Biogeografia, origem e distribuição da domiciliação de triatomíneos no Brasil. Rev S Públ São Paulo 1980; 15: 265-299.

10. Martins AV. Epidemiologia. In: Cançado JR, editor. Doença de Chagas. Belo Horizonte: Imprensa Oficial; 1968. p. 225-260.

11. Carlier Y, Dias JCP, Luquetti AO, Hontebeiryer M, Torrico F, Truyens C. Trypanosomiase américaine ou maladie de Chagas. In: Encyclopedie Médico Chirurgicale. Paris: Elsevier; 2002. p. 8-505-A-20, 21.

12. Teixeira A. Os jogos eônicos. In: Teixeira A, editors. Doença de Chagas e evolução. Brasília: Editora UNB; 2007. p. 27-50.

13. Dias JCP, Dias RB. Aspectos sociais, econômicos e culturais da doença de Chagas. Ci Cultura 1979: 31 (supl):105-118.

14. Dias JCP. Carlos Chagas: alguns aspectos históricos. Rev Patol Trop 2000; 29 (supl 1): 19-30.

15. Velazco OC, Rivas BS. Apuntes para la Historia de la Enfermedad de Chagas en México [Monografia]. México DF: Faculdade de Medicina da Universidade Nacional do México; 2007.

16. Chagas CRJ. Moléstia de Carlos Chagas. Segunda Conferência realizada na Academia Nacional de Medicina. In: Prata AR, editor. Carlos Chagas, coletânea de trabalhos científicos. Brasília, DF: Universidade de Brasília; 1981. p.167-192.

17. Dias JCP, Schofield CJ. The evolution of Chagas Disease control after 90 years since Carlos Chagas Discovery. Mem Inst Oswaldo Cruz 1999; 94 (suppl 1):103-121.

18. Dias JCP. História Natural da Doença de Chagas [Monografia] Belo Horizonte: Academia Mineira de Medicina; 2006.

19. Dias JCP. Cecílio Romaña, o sinal de Romaña e a doença de Chagas. Rev Soc Bras Med Trop 1997; 30: 407-413.

20. Prata AR. Clinical and epidemiological aspects of Chagas disease. Lancet Infect Dis 2001; 7: 572-100.
21. Chagas CRJ. Tripanosomíase americana. Forma aguda da moléstia. Mem Inst Oswaldo Cruz 1916; 8: 153-158.

22. Talice R, Costa RS, Rial B, Osimani JJ. Enfermedad de Chagas (Tripanosomiasis americana). Montevideo: Palacio Del Libro; 1940.

23. Chagas CRJ. Nova entidade mórbida do homem. Arch Soc Méd Cirurg S Paulo 1910; 1: 255-292.

.24. Chagas CRJ. Estado atual da tripanossomíase americana. Rev Biol Hyg 1934; 5: 58-64.

25. Coura JR. Síntese histórica e evolução dos conhecimentos sobre a doença de Chagas. In: Dias JCP, Coura JR, editores. Clínica e Terapêutica da doença de Chagas. Uma abordagem prática para o clínico geral. Rio de Janeiro: Editora Fiocruz; 1997. p. 469-486.

26. Sierra Iglesias JP. Salvador Mazza. Su vida y su obra. San Salvador de Jujuy, Universidad Nacional de Jujuy; 1990.

27. Laranja FS, Dias E, Nóbrega GC,Miranda A. Chagas' disease: a clinical, epidemiologic and pathologic study. Circulation 1956; 14:1035-1060.

28. Villela EA. A ocorrência da moléstia de Chagas nos hospitais de Belo Horizonte e na população de seus arredores. Bol Acad Nac Med 1930; 102: 122-156.

29. Laranja FS. Evolução dos conhecimentos sobre a cardiopatia chagásica. Revisão crítica da Literatura. Mem. Inst Oswaldo Cruz 1949; 47: 605-669.

30. Dias JCP Etiologia chagásica do megaesôfago chagásico no Brasil Rev Patol Trop 2001; 30: 135-142.

31. Chernoviz PLN. Dicionário de Medicina Popular, $2^{\text {a }}$ ed. Paris, Rio de Janeiro: Casa do Autor; 1868.

32. Dias E, Laranja FS, Nóbrega GC. Doença de Chagas. Mem Inst Oswaldo Cruz 1945; 43: 495-591.

33. Dias JCP, Rezende JM. Participação de Carlos Chagas e seus colaboradores no conhecimento e reconhecimento do megaesôfago de etiologia chagásica. Rev Patol Trop 2007; 36: 35-46.

34. Etzel E. Os primórdios do mal de engasgo no Brasil. Rev Patol Trop 1999; 28: 01-13.

35. Vampré E. Contribuição ao estudo do mal de engasgo. Serviço Sanitário do Estado de S. Paulo 1919; 5: 3-78.

36. Neiva A, Penna B. Viagem científica pelo norte da Bahia, sudoeste de Pernambuco, sul do Piauí e norte e sul de Goiás. Mem Inst Oswaldo Cruz 1916; 8(3): 73-224.

37. Köberle F. Patogênese dos megas. Rev Goiana Med 1956; 2: 101-110.

38. Rezende JM. Obstáculos ao reconhecimento da etiologia chagásica do megaesôfago e do megacólon endêmicos. In: Rezende JM, editors. Vertentes da Medicina. São Paulo: Editora Giordano; 2001. p. 349-364.

39. Rezende JM. Acredita que existem "megas" em todas as regiões em que a doença de Chagas é endêmica? In: Prata AR, editor. Reunião sobre diferenças geográficas ns doença de Chagas. Brasília: Universidade de Brasília; 1975. p. 145-154.

40. Schmunis GA.Medical significance of American Trypanosomiasis. In: Maudlin I, Holmes PH, Miles MA editors, The Trypanosomiasis. London: CABI Publishing; 2003: p.355-368.

41. Dias JCP, Silveira AC, Schofield CJ. The impact of Chagas Disease control in Latin America - A review. Mem Inst Oswaldo Cruz 2002; 97: 603-612.

42. Macêdo VO. Influência da exposição à reinfecção na evolução da doença de Chagas. Estudo longitudinal de cinco anos. Rev Patol Trop 1976; 5: 33-116.

43. Dias E. Os efeitos da superinfecção sobre a evolução da cardiopatia crônica chagásica. Rev Goiana Med 1963; 9 (supl): 233-239. 